\title{
Diagnosing and managing sleep apnea in patients with chronic cerebrovascular disease: a randomized trial of a home-based strategy
}

\author{
Dawn M. Bravata 1,2,3,4,5 - Vincent McClain ${ }^{5}$ - Charles Austin ${ }^{3}$ - Jared Ferguson ${ }^{3}$. \\ Nicholas Burrus ${ }^{1,2}$ • Edward J. Miech ${ }^{1,2,5,6}$ - Marianne S. Matthias ${ }^{1,5,7}$. \\ Neale Chumbler ${ }^{8}$ • Susan Ofner ${ }^{9}$ - Brian Foresman ${ }^{3,10}$ • Jason Sico 11,12,13 . \\ Carlos A. Vaz Fragoso ${ }^{11,12}$ - Linda S. Williams ${ }^{1,2,4,5}$ - Rajiv Agarwal ${ }^{3,10}$. \\ John Concato $^{12,14}$ - H. Klar Yaggi ${ }^{11,12}$
}

Received: 2 March 2017 / Accepted: 20 March 2017 /Published online: 6 April 2017

(C) The Author(s) 2017. This article is published with open access at Springerlink.com

\begin{abstract}
Background Obstructive sleep apnea is common and associated with poor outcomes after stroke or transient ischemic attack (TIA). We sought to determine whether the intervention strategy improved sleep apnea detection, obstructive sleep apnea (OSA) treatment, and hypertension control among patients with chronic cerebrovascular disease and hypertension. Methods In this randomized controlled strategy trial intervention, patients received unattended polysomnography at baseline, and patients with OSA (apnea-hypopnea index $\geq 5$ events/h) received auto-titrating continuous positive airway pressure (CPAP) for up to 1 year. Control patients received usual care and unattended polysomnography at the end of the
\end{abstract}

Dawn M. Bravata

Dawn.Bravata2@va.gov

1 VA HSR\&D Center of Excellence on Implementing Evidence-Based Practice (CIEBP), Richard L. Roudebush VA Medical Center, HSR\&D Mail Code 11H, 1481 West 10th Street, Indianapolis, IN 46202, USA

2 VA Health Services Research and Development (HSR\&D) Stroke Quality Enhancement Research Initiative (QUERI), Indianapolis, IN, USA

3 Department of Internal Medicine, Indiana University School of Medicine, Indianapolis, IN, USA

4 Department of Neurology, Indiana University School of Medicine, Indianapolis, IN, USA

5 Regenstrief Institute, Indianapolis, IN, USA

6 Department of Emergency Medicine, Indiana University School of Medicine, Indianapolis, IN, USA study, to identify undiagnosed OSA. Both groups received 24$\mathrm{h}$ blood pressure assessments at baseline and end of the study. "Excellent" CPAP adherence was defined as cumulative use of $\geq 4 \mathrm{~h} /$ night for $\geq 70 \%$ of the nights.

Results Among 225 randomized patients (115 control; 110 intervention), 61.9\% (120/194) had sleep apnea. The strategy successfully diagnosed sleep apnea with $97.1 \%(102 / 105)$ valid studies; $90.6 \%$ (48/53, 95\% CI 82.7-98.4\%) of sleep apnea was undiagnosed among control patients. The intervention improved long-term excellent CPAP use: $38.6 \%$ (22/57) intervention versus $0 \%(0 / 2)$ control $(p<0.0001)$. The intervention did not improve hypertension control in this population with well-controlled baseline blood pressure: intervention,

7 Department of Communication Studies, Indiana University-Purdue University at Indianapolis (IUPUI), Indianapolis, IN, USA

8 Health Policy and Management, University of Georgia, Athens, GA, USA

9 Department of Biostatistics, Indiana University School of Medicine, IUPUI, Indianapolis, IN, USA

10 Internal Medicine Service, Richard L. Roudebush VA Medical Center, Indianapolis, IN, USA

11 VA Connecticut Healthcare System, West Haven, CT, USA

12 Department of Internal Medicine, Yale University School of Medicine, New Haven, CT, USA

13 Department of Neurology, Yale University School of Medicine, New Haven, CT, USA

14 Clinical Epidemiology Research Center, VA Connecticut Healthcare System, West Haven, CT, USA 
$132.7 \mathrm{mmHg}$ ( \pm standard deviation, 14.1) versus control, $133.8 \mathrm{mmHg}( \pm 14.0)$ (adjusted difference, $-1.1 \mathrm{mmHg}$, $95 \%$ CI $(-4.2,2.0)), p=0.48)$.

Conclusions Patients with cerebrovascular disease and hypertension have a high prevalence of OSA. The use of portable polysomnography, and auto-titrating CPAP in the patients' homes, improved both the diagnosis and the treatment for sleep apnea compared with usual care but did not lower blood pressure.

Keywords Ischemic stroke $\cdot$ Transient ischemic attack $\cdot$ Sleep apnea diagnosis $\cdot$ Sleep apnea treatment

\section{Introduction}

Obstructive sleep apnea is found in at least half of individuals who have experienced an acute stroke or transient ischemic attack (TIA) [1-9]. Sleep apnea has been associated with a variety of adverse disease states and outcomes including hypertension, diabetes, ischemic stroke and transient ischemic attacks (TIA), incident coronary events and cardiovascular mortality, and all-cause mortality [3, 10-14]. Estimates suggest, however, that as many as $70-80 \%$ of the patients with sleep apnea are neither diagnosed nor treated [15]. The barriers to diagnosing and treating sleep apnea involve patient, provider, and system issues, including access to sleep laboratory-based testing [15].

The American Heart Association/American Stroke Association secondary stroke prevention guidelines recommend that patients with ischemic stroke and TIA receive screening for sleep apnea and treatment because of data suggesting that post-cerebrovascular event patient outcomes are improved with treatment of sleep apnea [16]. However, this guideline recommendation has not been adopted widely. For example, a recent report found that only $6 \%$ of the eligible patients received polysomnography in the year after an index cerebrovascular event [17].

The "Diagnosis and Treatment of Sleep Apnea in Cerebrovascular Disease" (GoToSleep) study evaluated a strategy to improve the diagnosis and treatment of sleep apnea among veterans with chronic ischemic stroke or TIA who also have hypertension [18]. Specifically, the GoToSleep study was designed to overcome some of the barriers that existed within the Veterans Health Administration (VHA) to the timely diagnosis and treatment of sleep apnea (e.g., limited mobility, travel distance) by using home-based ambulatory polysomnography and auto-titrating continuous positive airway pressure (CPAP) to reduce the reliance on laboratorybased sleep studies. The primary objectives of the GoToSleep study were to determine whether a diagnostic and therapeutic intervention strategy among veterans with chronic cerebrovascular disease and hypertension could improve: (1) the detection of sleep apnea; (2) the treatment for obstructive sleep apnea; and (3) the control of hypertension.

\section{Design and methods}

The GoToSleep study was a randomized controlled strategy trial conducted at two geographically distant Veterans Health Affairs (VHA) medical centers. The methods of this study have been described in detail elsewhere [18]. Briefly, patients with chronic cerebrovascular disease and hypertension were randomly assigned to an intervention group or a usual care control group. The randomization was stratified by medical center, baseline blood pressure, and risk of sleep apnea from the Berlin Questionnaire [19]. This study (NCT00984308) received institutional review board approval; patients provided written informed consent.

\section{Chronic cerebrovascular disease and hypertension patient definition}

Patients were included if they had a history of ischemic stroke or TIA and either a diagnosis of hypertension or a blood pressure of $\geq 140 / \geq 90 \mathrm{mmHg}$ [20]. This study was designed prior to the revision of the American Heart Association/ American Stroke Association definition of TIA, and employed the following definitions: an ischemic stroke is a persistent focal neurological deficit of presumed ischemic origin lasting more than $24 \mathrm{~h} \mathrm{[21]} \mathrm{and} \mathrm{a} \mathrm{TIA} \mathrm{is} \mathrm{a} \mathrm{focal} \mathrm{neuro-}$ logical deficit of presumed ischemic origin lasting less than $24 \mathrm{~h}$ [22]. Brain imaging was not required for the diagnosis of stroke or TIA. Patients were recruited at least 30 days after their most recent stroke and at any point after their most recent TIA.

\section{Measurements}

Patient interviews and medical record reviews were conducted to obtain information about demographics, comorbidities, medication use, and symptoms. Patients were examined to measure heart rate, neck circumference, height, and weight. The Berlin Questionnaire was used to classify patients according to "high" versus "low" risk for sleep apnea [19]. Daytime sleepiness was assessed using the Epworth Sleepiness Scale (ESS) with a score of $\geq 10$ indicating excessive daytime sleepiness [23, 24]. Neurological functioning was measured with the National Institutes of Health Stroke Scale (NIHSS) [25, 26].

\section{Blood pressure and antihypertensive medications}

Blood pressure measurements were taken at baseline and at the end of the study with a 24-h ambulatory monitor. Blood 
pressure data were classified as either sleeping or waking on the basis of actigraphy data or sleep diary information for patients with incomplete actigraphy data. Nocturnal blood pressure dipping patterns were assessed by comparing mean systolic blood pressure during sleep with mean systolic pressure during the wakeful state [27]. Antihypertensive medications were not changed as part of the study but were recorded at the time of the blood pressure measurements. The defined daily dose (DDD) of all antihypertensive medications was calculated using the World Health Organization (WHO) DDD methodology which allows for comparison across antihypertensive regimens [28]. The medication-adjusted mean systolic blood pressure was calculated from the 24-h mean systolic blood pressure measurement and the patient's DDD as follows: medication-adjusted systolic blood pressure $(\mathrm{SBP})=[$ mean systolic blood pressure in $\mathrm{mmHg}]+[$ the patient's DDD $\times(8.0 \mathrm{mmHg})][18]$.

\section{Polysomnography}

Intervention patients received full unattended (type 2) polysomnography at baseline (Safiro, Compumedics, Victoria, Australia). Control patients received polyso mnography at the end of the 1-year study period. Nearly all of the patients received the polysomnography in their homes. Full unattended polysomnography provided data on electroencephalogram (EEG), electrooculogram, chin electromyogram, thoracic and abdominal displacement, airflow, finger pulse oximeter, electrocardiogram, body position, leg movement, and audio recording of the participant's snoring. The polysomnographic data were read centrally and scored according to standard criteria [29]. An apnea-hypopnea index (AHI) was calculated as the number of respiratory events per hour of sleep [29-31]. Patients with an AHI $\geq 5$ events/h were diagnosed as having sleep apnea and were offered autotitrating CPAP [30]. Patients classified as having central sleep apnea or Cheyne-Stokes respiration were continued in the study but were referred for adaptive servoventilation (ASV). Patients with oxygen desaturations by polysomnography received one night of oximetry while using CPAP; patients with persistent desaturations despite auto-titrating CPAP were provided supplemental nocturnal oxygen via the CPAP machine.

\section{CPAP adherence support}

Our approach to improving CPAP adherence consisted of early intensive education and support, followed by regular and ongoing contact with patients. During the in-home visit where the results of the baseline polysomnography were reviewed, staff members provided patients with information about sleep apnea and CPAP. During the first month after delivery of the CPAP machine, the patient was visited each of the first 2 days and then weekly for the first month; thereafter, patients received monthly telephone calls for the remainder of the 1year study period. An in-home visit was scheduled after 6 months of CPAP use and also at the end of the study. During the in-home visits, staff downloaded pressure, residual AHI, air leak, and compliance data from the CPAP machine and reviewed these data with the patients. Staff members were also available to patients for ad hoc issues related to difficulties with mask fit or other technical problems with the CPAP machines.

\section{Usual care}

Control patients received usual care as directed by their physicians, including care of their vascular risk factors such as hypertension and referral for usual care sleep apnea testing. Control patients in the GoToSleep study were neither prohibited from nor specifically encouraged to receive polysomnography as part of their usual care. Control patients received unattended polysomnography at the end of the study period.

\section{Outcomes}

\section{Sleep apnea diagnosis}

The proportion of intervention and control patients with a diagnosis of obstructive or central sleep apnea was calculated from the unattended polysomnography performed in the intervention group and from any polysomnography that was performed as part of usual care among control patients. The primary outcome related to sleep apnea detection was the prevalence of undiagnosed sleep apnea in the control group which was determined using polysomnography data obtained as part of the research protocol at the end of the study.

\section{Obstructive sleep apnea treatment}

CPAP adherence was classified as "none" if the patient refused to take receipt of a CPAP machine or did not use the machine at all, "poor" if the nights of usage was $\leq 10 \%$ of total nights available, "some" if the total nights used $>10 \%$ of total nights available or the cumulative hours of use was $<4 \mathrm{~h}$ per night times $70 \%$ of the total nights available for use, and "excellent" if the total cumulative hours of use was $\geq 4 \mathrm{~h}$ per night times $70 \%$ of the total nights available for use [32]. The primary outcome related to obstructive sleep apnea treatment was the proportion of intervention and control patients with obstructive sleep apnea with excellent CPAP adherence. 


\section{Hypertension control}

The primary hypertension outcome was the final mean 24-h SBP, adjusted for baseline mean 24-h SBP. Our secondary hypertension analyses included the final medication-adjusted SBP, the final DDD, and the proportion of patients with a nocturnal decline ("dipping") in systolic blood pressure of $\geq 10 \%$ [27].

\section{Sample size}

The GoToSleep trial was designed to recruit 318 patients to have at least $80 \%$ power to detect the following prespecified differences in the three primary aims: $60 \%$ of the intervention patients compared with $10 \%$ of the control patients would be diagnosed with sleep apnea; $50 \%$ of the intervention patients diagnosed with sleep apnea as part of the study protocol, compared with $15 \%$ of the control patients diagnosed with sleep apnea as part of usual care, would use CPAP therapy; and the 1-year mean systolic blood pressure would be $125 \mathrm{mmHg}$ with a standard deviation of $20 \mathrm{mmHg}$ in the intervention group compared with $135 \mathrm{mmHg}$ with a standard deviation of $20 \mathrm{mmHg}$ in the control group. The sample size estimates assumed a $10 \%$ loss to follow-up in both the intervention and the usual care arms.

\section{Analyses}

The primary analyses were designed to be intention -totreat comparisons of the outcomes for patients in the intervention versus control groups. For the analysis of diagnosis rates, all patients were analyzed according to the group to which they had been randomly assigned regardless of subject study completion. Ninety five percent confidence intervals were calculated around the undiagnosed sleep apnea rate obtained from the control group. For the analysis of treatment rates, CPAP adherence was assessed among patients with obstructive sleep apnea. The comparison of final mean 24-h SBP was not restricted to patients with sleep apnea, but rather was conducted across all patients with final ambulatory blood pressure data, regardless of sleep study results. A secondary hypertension control analysis was pre-specified to be conducted among sleep apnea patients in the intervention group with or without excellent CPAP adherence, to examine the effect of CPAP use on antihypertensive outcomes.

Baseline characteristics were compared between intervention and control groups using Fisher's exact test, chisquared test, 2-sample $t$ test, or Wilcoxon 2-sample tests. Chi-squared tests were used to test for group differences in diagnosis and treatment rates. An analysis of covariance (ANCOVA) model, with terms for site, group, and baseline measure, was used to test for differences in mean final 24-h SBP. Residual plots were examined for possible violation of model assumptions. The final medicationadjusted SBP was analyzed similarly. Final DDD was rank transformed because of skewness and was analyzed similarly, including a squared baseline DDD term. Summary statistics of change in measures are presented but were not modeled or statistically tested, because the analyses of the final measurements included adjustment for baseline measurements. A logistic model with terms for site and group was used to estimate the effect of the intervention on the odds of having nocturnal decline of $\geq 10 \%$. A cumulative logistic model was used for the ordinal outcome of nocturnal dipping category and modeled the probability of having greater nighttime dipping. The proportional odds assumption was verified. The secondary analyses of hypertension control measures by CPAP adherence used similar models with the term for treatment group replaced by a variable for CPAP adherence (excellent versus not). No corrections for multiple comparisons were made, because we pre-specified a single primary outcome for the three primary aims. SAS ${ }^{\circledR}$ version 9.2 (Cary, NC) was used for all analyses.

\section{Results}

The medical records of $N=2395$ patients were screened for eligibility. Among the $N=1706$ (71.2\%) potentially eligible patients, $337(19.8 \%)$ refused and $1144(67.1 \%)$ met at least one exclusion criterion (Fig. 1). A total of 225 patients were included in the study: $N=110$ intervention and $N=115$ control. Overall, 24/225 (10.7\%) patients withdrew: 6 (5.2\%) from the control group and 18 (16.4\%) from the intervention group. The baseline characteristics of the patients are provided in Table 1.

\section{Sleep apnea diagnosis rate}

Polysomnography was conducted at the beginning of the study on 105 of the 110 intervention patients (Fig. 2); 102/ $105(97.1 \%)$ of these studies were valid (three studies had insufficient high-quality data to be scored). Among the 102 valid studies, $58(56.9 \%)$ had obstructive sleep apnea, 9 (8.8\%) had central sleep apnea, and 35 (34.3\%) had no sleep apnea. Polysomnography was completed as part of usual care in 7 of the 115 control patients $(7 / 115,6.1 \%) ; 5 / 7(71.4 \%)$ had obstructive sleep apnea, none had central sleep apnea, and 2/7 (28.6\%) had no sleep apnea. Polysomnography was performed at the end of the study, as part of the research protocol, on 91 control patients; 85/91 (93.4\%) were valid studies. Among the 85 valid studies obtained as part of the study protocol among control patients, $46(54.1 \%)$ had obstructive 


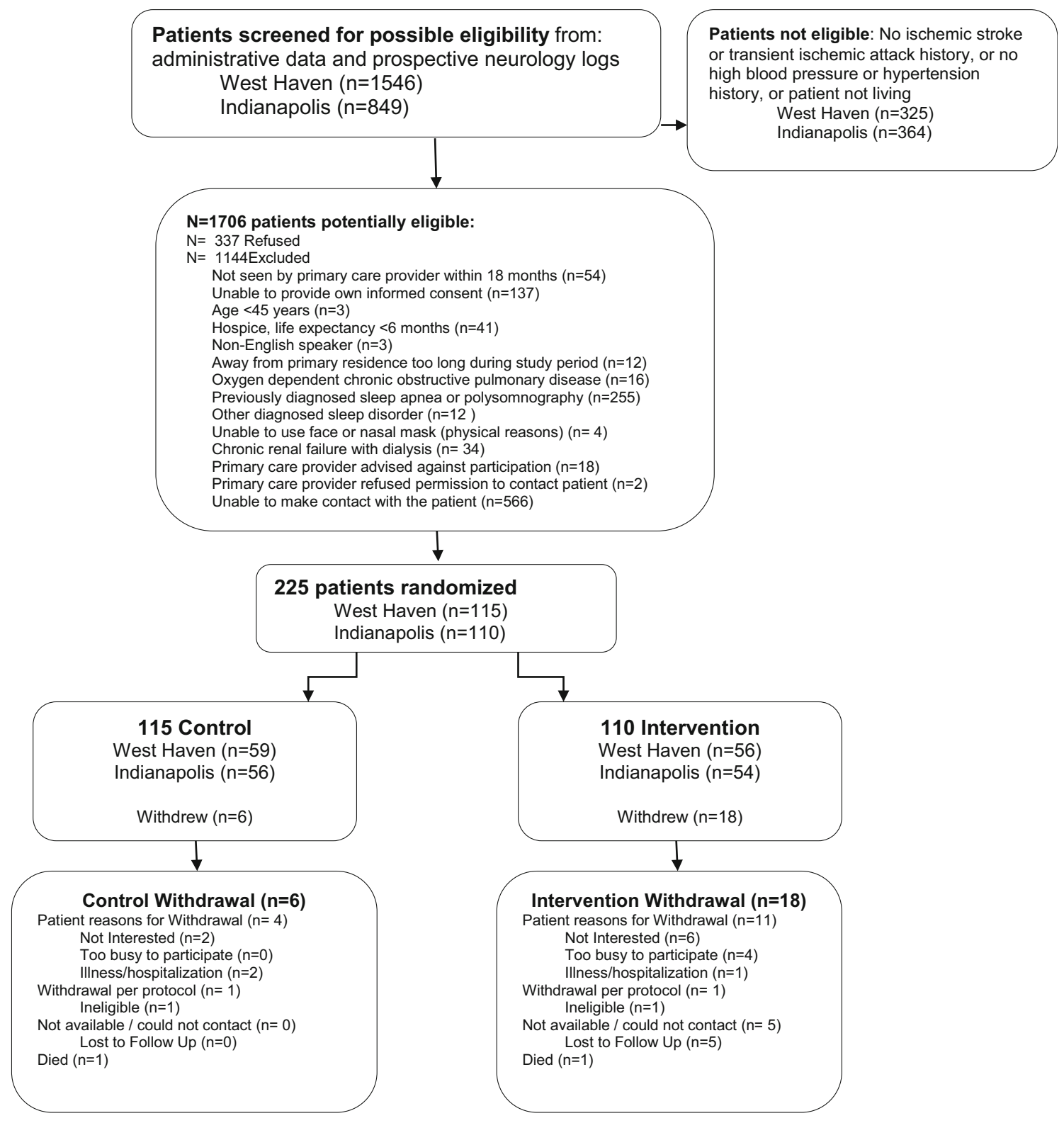

Fig. 1 Patient screening, recruitment, and retention flow

sleep apnea, 2 (2.4\%) had central sleep apnea, and 37 (43.5\%) had no sleep apnea. A total of 53 patients had sleep apnea in the control group: 51 with obstructive sleep apnea (5 diagnosed as part of usual care and 46 diagnosed as part of the study protocol) and 2 with central sleep apnea (all diagnosed as part of the study protocol). The prevalence of undiagnosed sleep apnea (from the control group) was $90.6 \%$ (48/53; $95 \%$ CI, 82.7 to $98.4 \%$ ) (Tables 2 and 3).

Overall (including both intervention and control patients), 61.9\% (120/194) of the patients had obstructive or central sleep apnea. The ESS was $\geq 10$ in $40 / 119$ (33.6\%) with sleep apnea and $23 / 75(30.7 \%)$ without sleep apnea $(p=0.67)$. The Berlin score was classified as high risk in $85 / 119(71.4 \%)$ with sleep apnea and 49/75 (65.3\%) without sleep apnea $(p=0.37)$.

\section{Obstructive sleep apnea treatment rate}

Among the five control patients who were diagnosed with obstructive sleep apnea as part of usual care (see Fig. 2), two patients did not receive CPAP during the study and one patient had missing CPAP use data. Among the two control patients with known CPAP use data, $0(0 \%)$ had excellent CPAP adherence; the mean number of hours used per night was $0.1 \mathrm{~h}$ (standard deviation 0.2); and the mean proportion of nights with any CPAP use was 0.07 (standard deviation 0.08). In contrast, among the 58 intervention patients who were diagnosed with obstructive sleep apnea during the study, 1 patient had missing CPAP use data, 22 (38.6\%) had excellent CPAP adherence, the mean number of hours used per night was $2.5 \mathrm{~h}$ (standard 
Table 1 Baseline characteristics

\begin{tabular}{|c|c|c|c|}
\hline Characteristic & $\begin{array}{l}\text { Intervention } \\
(N=110)\end{array}$ & $\begin{array}{l}\text { Control } \\
(N=115)\end{array}$ & $\begin{array}{l}p \\
\text { value }\end{array}$ \\
\hline Age (years): (range), median & $(45,91) 70$ & $(50,90) 70$ & \\
\hline Mean \pm standard deviation & $69.7 \pm 10.4$ & $70.2 \pm 10.1$ & 0.81 \\
\hline White race: $N(\%)$ & $82(74.6)$ & $92(80.0)$ & 0.33 \\
\hline Male sex: $N(\%)$ & $109(99.1)$ & $110(95.7)$ & 0.21 \\
\hline Excessive daytime sleepiness (ESS $\geq 10$ ): $N(\%)$ & $36(32.4)$ & $28(24.1)$ & 0.17 \\
\hline \multicolumn{4}{|l|}{ Index cerebrovascular event ${ }^{\mathrm{a}}$} \\
\hline Stroke: $N(\%)$ & $75(68.2)$ & $87(75.7)$ & 0.21 \\
\hline Transient ischemic attack (TIA): $N(\%)$ & $49(44.6)$ & $45(39.1)$ & 0.41 \\
\hline $\begin{array}{l}\text { Time from most recent event to enrollment (year): (range) } \\
\text { median }\end{array}$ & $(0,44) 4$ & $(0,65) 4$ & \\
\hline Mean \pm standard deviation & $6.2 \pm 7.4$ & $7.3 \pm 9.2$ & 0.45 \\
\hline \multicolumn{4}{|l|}{ Comorbidity: $N(\%)$} \\
\hline Hypertension & $110(100.0)$ & $115(100.0)$ & \\
\hline On any antihypertensive medication & $104(94.6)$ & $111(96.5)$ & 0.53 \\
\hline Hyperlipidemia & $88(80.0)$ & $96(83.5)$ & 0.50 \\
\hline Diabetes mellitus & $51(46.4)$ & $40(34.8)$ & 0.08 \\
\hline Chronic pain & $42(38.2)$ & $31(27.0)$ & 0.07 \\
\hline Depression & $39(35.5)$ & $37(32.2)$ & 0.60 \\
\hline Current tobacco smoking: $N(\%)$ & $32(29.1)$ & $32(27.8)$ & 0.83 \\
\hline Chronic obstructive pulmonary disorder (COPD) & $26(23.6)$ & $21(18.3)$ & 0.32 \\
\hline Myocardial infarction & $25(22.7)$ & $30(26.1)$ & 0.56 \\
\hline Anxiety & $23(20.9)$ & $13(11.3)$ & 0.05 \\
\hline Peripheral vascular disease & $19(17.3)$ & $26(22.6)$ & 0.32 \\
\hline Atrial fibrillation & $11(10.0)$ & $19(16.5)$ & 0.15 \\
\hline Chronic kidney disease & $10(9.1)$ & $11(9.6)$ & 0.90 \\
\hline Dementia & $10(9.1)$ & $6(5.2)$ & 0.26 \\
\hline Congestive heart failure & $9(8.2)$ & $14(12.2)$ & 0.32 \\
\hline Charlson comorbidity score: mean \pm standard deviation & $2.6 \pm 2.2$ & $2.3 \pm 2.2$ & 0.25 \\
\hline \multicolumn{4}{|l|}{ Measurements } \\
\hline Neck circumference (inches): mean \pm standard deviation & $16.4 \pm 1.5$ & $16.3 \pm 1.3$ & 0.87 \\
\hline Waist circumference (inches): mean \pm standard deviation & $41.3 \pm 5.2$ & $42.2 \pm 5.1$ & 0.19 \\
\hline Weight (pounds): mean \pm standard deviation & $188.6 \pm 34.3$ & $193.4 \pm 34.7$ & 0.19 \\
\hline Body mass index $\left(\mathrm{kg} / \mathrm{m}^{2}\right)$ : mean \pm standard deviation & $38.5 \pm 12.9$ & $39.6 \pm 12.9$ & 0.45 \\
\hline NIH Stroke Scale: (range) median & $(0,12), 1.0$ & $(0,19), 1.0$ & \\
\hline Mean \pm standard deviation & $2.2 \pm 2.7$ & $2.0 \pm 3.1$ & 0.51 \\
\hline Systolic blood pressure (mmHg): (range) median & $(86,184) 132$ & $(94,190) 134$ & \\
\hline Mean \pm standard deviation & $132.1 \pm 19.3$ & $133.8 \pm 17.3$ & 0.43 \\
\hline Diastolic blood pressure (mmHg): (range) median & $(36,100) 72$ & $(50,102) 72$ & \\
\hline Mean \pm standard deviation & $71.6 \pm 11.9$ & $72.5 \pm 11.3$ & 0.72 \\
\hline $\begin{array}{l}\text { 24-h mean systolic blood pressure }(\mathrm{mmHg}) \text { : range, } \\
\text { median }\end{array}$ & $\begin{array}{l}(97.2,176.5) \\
134.4\end{array}$ & $\begin{array}{l}(98.7,178.5) \\
136.8\end{array}$ & \\
\hline Mean \pm standard deviation & $134.2 \pm 14.1$ & $136.1 \pm 13.3$ & 0.32 \\
\hline $\begin{array}{l}\text { 24-h mean diastolic blood pressure }(\mathrm{mmHg}) \text { : range, } \\
\text { median }\end{array}$ & $(51.7,97.5) 72.0$ & $\begin{array}{l}(51.1,116.8) \\
72.2\end{array}$ & \\
\hline Mean \pm standard deviation & $72.3 \pm 10.1$ & $73.8 \pm 11.4$ & 0.48 \\
\hline $\begin{array}{l}\text { Antihypertensive medication defined daily dose (DDD): } \\
\text { (range), median }\end{array}$ & $(0.0,9.5) 2.7$ & $(0.0,9.7) 2.7$ & \\
\hline Mean \pm standard deviation & $2.9 \pm 2.3$ & $3.1 \pm 2.3$ & 0.43 \\
\hline Medication-adjusted SBP ( $\mathrm{mmHg}$ ): range, median & $\begin{array}{l}(116.3,226.8) \\
155.0\end{array}$ & $\begin{array}{l}(100.7,232.0) \\
157.4\end{array}$ & \\
\hline Mean \pm standard deviation & $157.4 \pm 25.0$ & $161.6 \pm 24.3$ & 0.17 \\
\hline
\end{tabular}


Table 1 (continued)

\begin{tabular}{llll}
\hline Characteristic & $\begin{array}{l}\text { Intervention } \\
(N=110)\end{array}$ & $\begin{array}{l}\text { Control } \\
(N=115)\end{array}$ & $\begin{array}{l}p \\
\text { value }\end{array}$ \\
\hline Nocturnal blood pressure dipping patterns: $N(\%)$ & & & \\
Extreme: $\geq 20 \%$ fall in SBP at night/sleep & $3(3.1)$ & $5(4.9)$ & 0.60 \\
Normal: $\geq 10$ but $<20 \%$ fall in SBP at night/sleep & $21(21.7)$ & $15(14.6)$ & \\
None: $<10$ to $\leq 0 \%$ fall at night/sleep & $43(44.3)$ & $50(48.5)$ & \\
Reverse: SBP, sleep $>$ wakefulness & $30(30.9)$ & $33(32.0)$ \\
\hline
\end{tabular}

ESS Epworth Sleepiness Scale, SBP systolic blood pressure

${ }^{\mathrm{a}}$ All patients in this cohort had a history of a cerebrovascular event and hypertension

deviation 2.8), and the proportion of nights with any CPAP use was 0.45 (standard deviation 0.40). The intervention patients were much more likely to have excellent CPAP adherence than the control patients: $38.6(22 / 57)$ versus $0 \%(0 / 2), p<0.0001$.

Figure 3 provides a graphical illustration of CPAP adherence over time with hours per night used on the $y$-axis and nights in the study on the $x$-axis. These data suggest that CPAP use varied considerably over time and that there was no consistent point in time after which CPAP use stabilized.

\section{Hypertension control}

The blood pressure was relatively well controlled at baseline in this population of patients (Table 1). The baseline mean
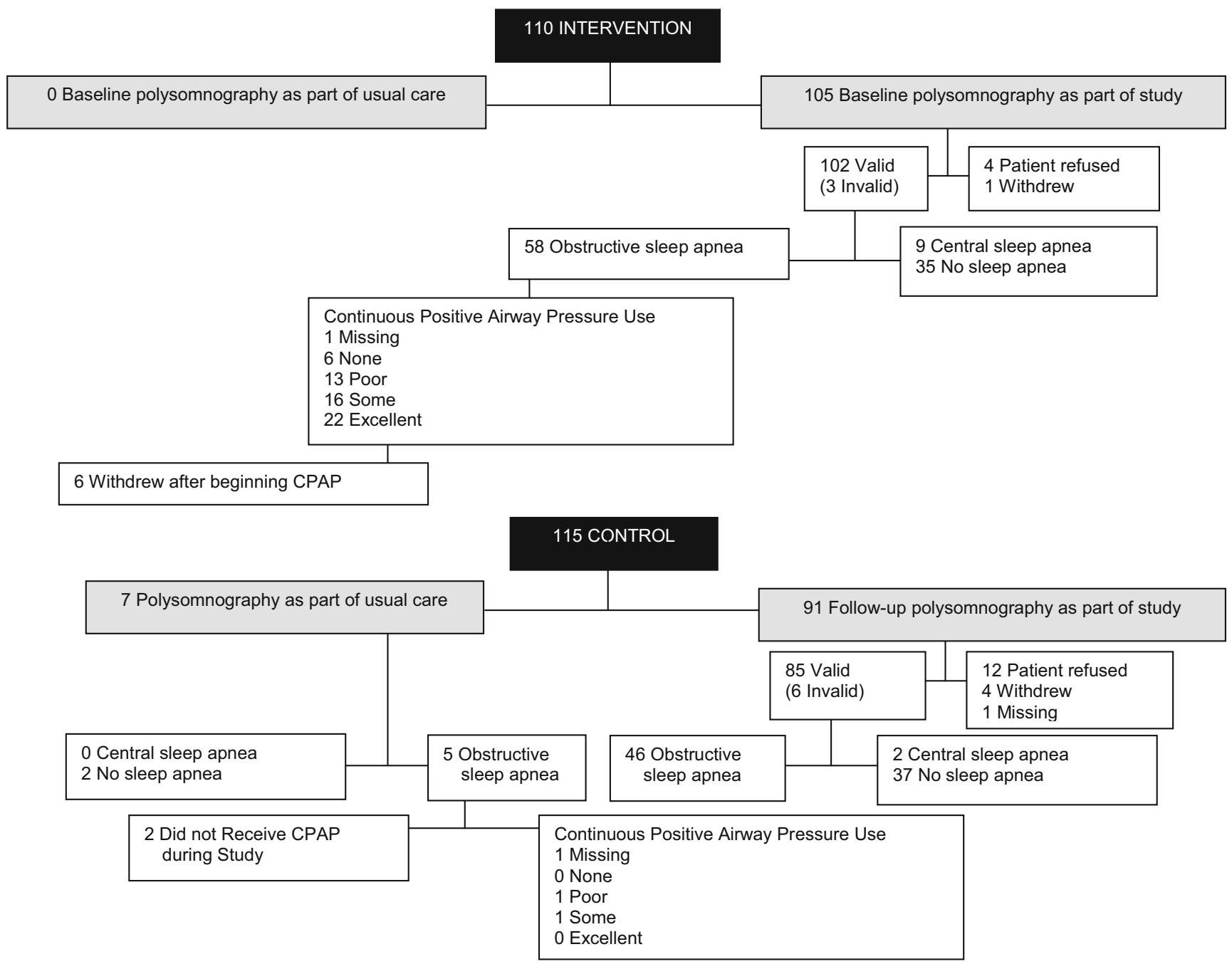

Fig. 2 Receipt of polysomnography and continuous positive airway pressure 
Table 2 Polysomnographic data

\begin{tabular}{llll}
\hline $\begin{array}{l}\text { Characteristic } \\
\text { Number of valid sleep studies }\end{array}$ & $\begin{array}{l}\text { Overall } \\
(n=194)\end{array}$ & $\begin{array}{l}\text { Intervention } \\
(n=102)\end{array}$ & $\begin{array}{l}\text { Control } \\
(n=92)^{\mathrm{a}}\end{array}$ \\
\hline $\begin{array}{l}\text { Apnea-hypopnea index (AHI, events/h): (range) median } \\
\quad \text { Mean } \pm \text { standard deviation }\end{array}$ & $\begin{array}{l}(0,87.2) 7.5 \\
14.3 \pm 16.1\end{array}$ & $\begin{array}{l}(0,87.2) 7.6 \\
15.0 \pm 16.6\end{array}$ & $\begin{array}{l}(0,64.9) 7.3 \\
13.6 \pm 15.7\end{array}$ \\
$\begin{array}{l}\text { Central apnea index: mean } \pm \text { standard deviation } \\
\text { Polysomnography results: } N(\%)\end{array}$ & $2.2 \pm 6.7$ & $2.9 \pm 8.4$ & $1.3 \pm 3.5$ \\
$\quad$ Obstructive sleep apnea & $109(56.2)$ & $58(56.9)$ & $51(55.4)$ \\
$\quad$ AHI: mean \pm standard deviation & $21.2 \pm 15.6$ & $20.0 \pm 15.2$ & $22.6 \pm 16.1$ \\
$\quad$ Central sleep apnea & $11(5.6)$ & $9(8.8)$ & $2(2.2)$ \\
$\quad$ No sleep apnea & $74(38.1)$ & $35(34.3)$ & $39(42.4)$ \\
\hline
\end{tabular}

${ }^{\mathrm{a}}$ The valid sleep studies in the control group include the 85 obtained as part of the study and 7 obtained as part of routine clinical care

24-h systolic blood pressure was $134.2 \mathrm{mmHg}( \pm 14.1)$ for intervention patients and $136.1 \mathrm{mmHg}( \pm 13.3)$ for control patients $(p=0.32)$. The overwhelming majority of patients (94.6\% of the intervention patients and $96.5 \%$ of the control patients, $p=0.53$ ) were taking at least one antihypertensive medication. The intervention strategy did not significantly improve blood pressure control; the final mean 24-h systolic blood pressure was nearly identical in the two groups: intervention, $132.7 \mathrm{mmHg}$ ( \pm standard deviation of 14.1 ); control, $133.8 \mathrm{mmHg}( \pm 14.0 ; p=0.48$; Table 4$)$. When restricting the analysis to intervention patients with sleep apnea, no difference in the change in mean 24-h systolic blood pressure was identified for patients with excellent $(-1.1 \mathrm{mmHg})$ versus not excellent $(-1.1 \mathrm{mmHg})$ CPAP adherence (Table 5). Both final and change in medicationadjusted 24-h SBP favored the excellent use group, but the difference between mean final medication adjusted SBP was not statistically significant (excellent, $149.4 \mathrm{mmHg}$; not excellent $166.9 \mathrm{mmHg} ; p=0.40$ ).

\section{Discussion}

These results demonstrate that sleep apnea is very common among patients with chronic cerebrovascular disease and hypertension; the observed prevalence of 120/194 (62\%) is similar to rates observed in studies that have primarily focused on acute and subacute cerebrovascular disease populations [1-9]. These results also demonstrate that a strategy of diagnosing and treating sleep apnea in the homes of patients with chronic cerebrovascular disease and hypertension can lead to substantial improvements in the detection of sleep apnea and in treatment with CPAP.

Usual care identified less than one in ten patients who actually had sleep apnea, a rate that leaves considerable room for improvement. Moreover, the sleep apnea that was detected in this study population included some patients with very high AHIs indicative of severe disease; therefore, it is incorrect to assume that only mild sleep apnea remained undetected by usual care. Only 64/225 (28\%) participants in this study had excessive daytime sleepiness according to the Epworth Sleepiness Scale, indicating that "typical" patient characteristics that might alert primary care providers to the need for performing polysomnography were uncommon. Specifically, neither the Epworth Sleepiness Scale nor the Berlin Questionnaire was useful in identifying patients with sleep apnea in this study. It is unknown whether aging or cerebrovascular disease may contribute to a reduced perception of drowsiness. In the absence of validated and reliable methods of screening for polysomnography in the post-stroke and postTIA populations $[33,34]$, it is reasonable to use polysomnography to identify sleep apnea given the high underlying prevalence of sleep apnea in this population and the known consequences of untreated sleep apnea.

Because testing for sleep apnea was so uncommon in the usual care group in this study, the number of patients who were eligible for treatment as part of usual care was very small; this limited our assessment of CPAP adherence in usual care versus the intervention groups. None of the usual care patients used CPAP for the recommended $\geq 4 \mathrm{~h}$ per night for $\geq 70 \%$ of the nights, whereas $38.6 \%$ (22/57) of the intervention

Table 3 Detection of sleep apnea rates

\begin{tabular}{|c|c|c|c|c|c|}
\hline Population & Intervention $(N=110)$ & Control $(N=115)$ & $p$ value & Difference & $95 \% \mathrm{CI}$ \\
\hline Sleep apnea identified among all patients & $67 / 110(60.9 \%)$ & $5 / 115(4.4 \%)$ & $<0.0001$ & $56.6 \%$ & $(46.7,66.4)$ \\
\hline Sleep apnea identified among patients with sleep apnea & $67 / 67(100.0 \%)$ & $5 / 53(9.4 \%)$ & $<0.0001$ & $90.6 \%$ & $(82.7,98.4)$ \\
\hline
\end{tabular}

Sleep apnea refers to either obstructive or central sleep apnea 
Fig. 3 Patterns of continuous positive airway pressure over a 1 -year period

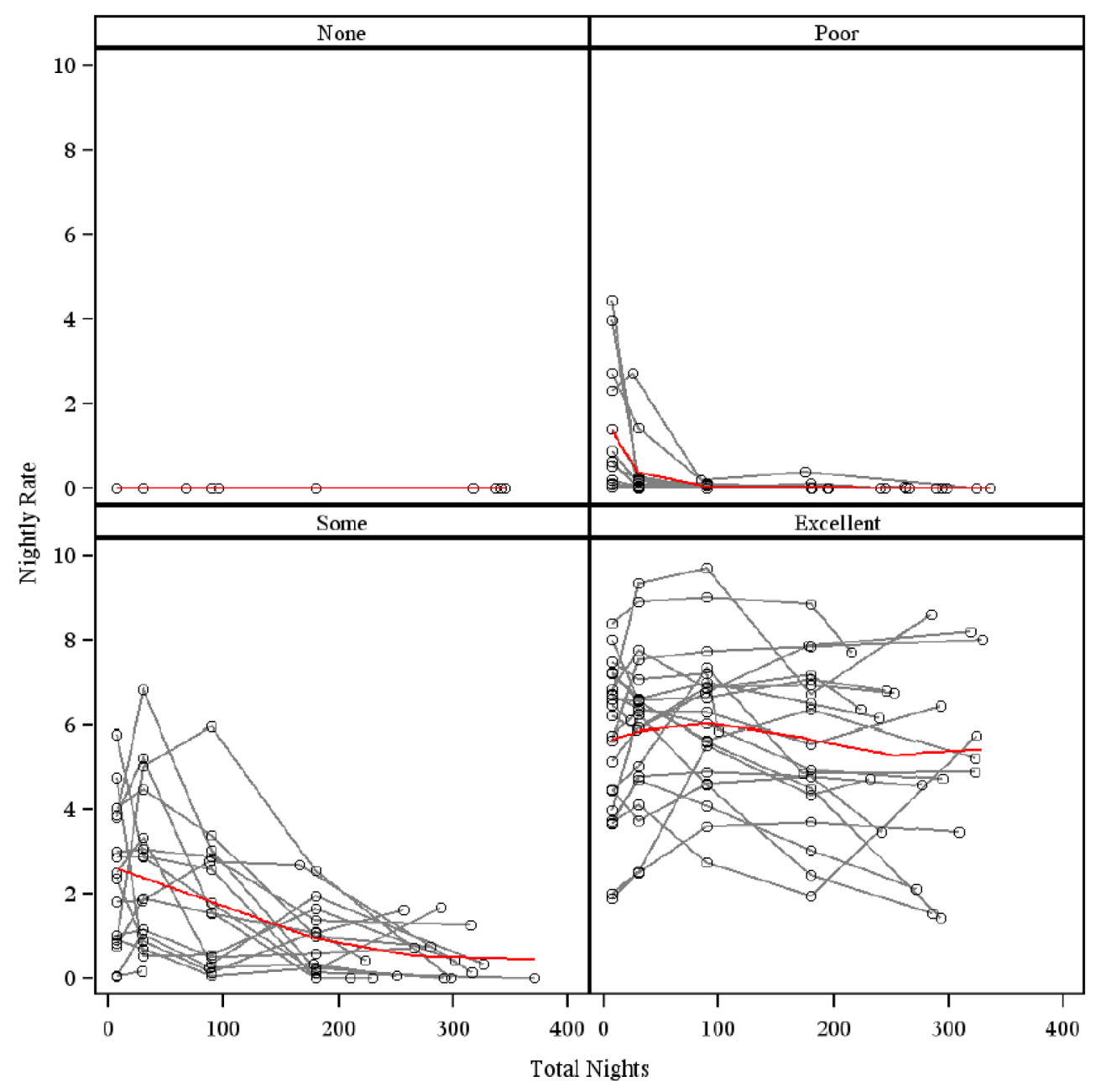

patients achieved this degree of adherence. The two VHA medical centers differed in their approach to usual care. One provided CPAP mask fitting and education via a contract with a home health agency, and the other provided these services via an on-site durable medical equipment (DME) CPAP clinic. Both sites provided a visit with a trained sleep staff member after 30 days, and as-needed support related to mask fit or equipment functioning. In general, usual care at these two sites is similar to sleep care received in the non-VHA setting. The intervention patients, in contrast, had both more frequent contact with staff and the content of the contact was different from usual care. In particular, the staff worked with patients to identify salient motivators for using CPAP (e.g., having more energy to play with grandchildren) and salient barriers inhibiting CPAP use (e.g., nasal stuffiness). As the patients began to use the CPAP, their salient positives and negatives might have changed, but the staff consistently sought to identify methods to overcome those barriers and remind patients of their individual reasons for trying the CPAP. In this way, the content of the visits was not only focused on technical issues related to mask fit, leak, and humidification but also on motivators to try CPAP and to persist over time. In this study,
CPAP adherence was not associated with physical impairments (data not shown). Even patients with hemiparesis and blindness were able to achieve excellent CPAP adherence with adequate support from study staff and from caregivers.

This study did not identify a difference in blood pressure management for intervention versus control patients. Three key reasons likely contributed to this negative finding. First, the sample size of this trial was designed to detect a $10-\mathrm{mmHg}$ difference in mean 24-h systolic blood pressure and this study did not achieve the anticipated sample size $(N=225$ versus $n=318$ ). Our inability to achieve the targeted sample size was principally due to delays in hiring and training needed staff within the VHA human resource constraints and because patients who were included in the study lived further away from the medical center than in our pilot work; hence, the resources needed (e.g., staff time, mileage reimbursement) to provide inhome polysomnography and CPAP support were greater than expected. Moreover, several meta-analyses have been published since the time of designing this trial which suggest that the actual difference in systolic blood pressure that can be expected with CPAP ranges from -1.4 to $-7.2 \mathrm{mmHg}$ [35-38], with most of the estimates closer to the $1.4 \mathrm{mmHg}$ 
Table 4 Hypertension control: intention to treat analysis

\begin{tabular}{|c|c|c|c|c|c|c|}
\hline \multirow[t]{2}{*}{ Blood pressure outcomes } & \multirow[t]{2}{*}{$\begin{array}{l}\text { Intervention } \\
(N=110)\end{array}$} & \multirow[t]{2}{*}{$\begin{array}{l}\text { Control } \\
(N=115)\end{array}$} & \multicolumn{2}{|c|}{$\begin{array}{l}\text { Adjusted final means } \\
\text { (standard error) }\end{array}$} & \multirow{2}{*}{$\begin{array}{l}\text { Adjusted mean } \\
\text { difference }(95 \% \mathrm{CI}) \\
\text { intervention versus } \\
\text { control }\end{array}$} & \multirow[t]{2}{*}{$\begin{array}{l}p \\
\text { value }\end{array}$} \\
\hline & & & Intervention & Control & & \\
\hline Final mean 24-h SBP (mmHg): (range), median & $\begin{array}{l}(102.4,173.7) \\
132.0\end{array}$ & $\begin{array}{l}(107.9,174.1) \\
132.9\end{array}$ & $132.8(1.2)$ & $133.9(1.1)$ & $-1.1(-4.2,2.0)$ & 0.48 \\
\hline Mean \pm standard deviation & $132.7 \pm 14.1$ & $133.8 \pm 14.0$ & & & & \\
\hline Change in mean 24-h SBP (mmHg): (range), median & $(-44.4,29.4)-0.5$ & $\begin{array}{l}(-42.9,26.3) \\
-0.1\end{array}$ & & & & \\
\hline Mean \pm standard deviation & $-2.4 \pm 12.5$ & $-1.6 \pm 11.3$ & & & & \\
\hline $\begin{array}{l}\text { Final DDD: (range), median } \\
\quad \text { Mean } \pm \text { standard deviation }\end{array}$ & $\begin{array}{l}(0.0,10.1) 2.5 \\
3.0 \pm 2.5\end{array}$ & $\begin{array}{l}(0.0,11.5) 2.7 \\
3.2 \pm 2.2\end{array}$ & $3.1(0.1)$ & $3.1(0.1)$ & $0.0(-0.4,0.4)$ & 0.51 \\
\hline $\begin{array}{l}\text { Change in DDD: (range), median } \\
\text { Mean } \pm \text { standard deviation }\end{array}$ & $\begin{array}{l}(-3.0,4.8) 0.0 \\
0.1 \pm 1.2\end{array}$ & $\begin{array}{l}(-5.0,5.3) 0.0 \\
0.0 \pm 1.5\end{array}$ & & & & \\
\hline $\begin{array}{l}\text { Final medication-adjusted SBP (mmHg): (range), } \\
\text { median } \\
\text { Mean } \pm \text { standard deviation }\end{array}$ & $\begin{array}{l}(112.8,240.1) \\
154.1 \\
157.3 \pm 28.2\end{array}$ & $\begin{array}{l}(110.0,248.5) \\
156.8 \\
158.8 \pm 25.5\end{array}$ & $158.4(1.7)$ & $158.7(1.6)$ & $-0.2(-4.8,4.4)$ & 0.93 \\
\hline $\begin{array}{l}\text { Change in medication-adjusted SBP (mmHg): } \\
\text { (range), median }\end{array}$ & $(-50.6,39.8)-0.2$ & $(-42.9,45.0) 0.5$ & & & & \\
\hline Mean \pm standard deviation & $-1.3 \pm 16.7$ & $-1.3 \pm 15.8$ & & & & \\
\hline $\begin{array}{l}\text { Final nocturnal blood pressure dipping patterns: } n \\
(\%)\end{array}$ & & & & & Odds ratio $(95 \% \mathrm{CI})$ & \\
\hline Extreme: $\geq 20 \%$ fall in SBP at night/sleep & $2(1.8)$ & $2(1.7)$ & & & $0.96(0.55,1.71)$ & 0.90 \\
\hline Normal: $\geq 10$ but $<20 \%$ fall in SBP at night/sleep & $16(14.6)$ & $17(14.8)$ & & & & \\
\hline None: $<10$ to $\leq 0 \%$ fall at night/sleep & $40(36.4)$ & $49(42.6)$ & & & & \\
\hline $\begin{array}{l}\text { Reverse: SBP at night/sleep greater than } \\
\text { daytime/awake }\end{array}$ & $22(20.0)$ & $23(20.0)$ & & & & \\
\hline
\end{tabular}

Modeling the probability of having greater nighttime dipping

Table 5 Hypertension control: among sleep apnea patients

\begin{tabular}{|c|c|c|c|c|c|c|}
\hline \multirow[t]{2}{*}{ Blood pressure outcomes } & \multicolumn{2}{|c|}{$\begin{array}{l}\text { Continuous positive airway } \\
\text { pressure adherence }\end{array}$} & \multicolumn{2}{|c|}{$\begin{array}{l}\text { Adjusted final means } \\
\text { (standard error) }\end{array}$} & \multirow{2}{*}{$\begin{array}{l}\text { Adjusted mean } \\
\text { difference }(95 \% \mathrm{CI}) \\
\text { excellent versus not }\end{array}$} & \multirow[t]{2}{*}{$\begin{array}{l}p \\
\text { value }\end{array}$} \\
\hline & $\begin{array}{l}\text { Not excellent } \\
(N=35)\end{array}$ & $\begin{array}{l}\text { Excellent } \\
(N=22)\end{array}$ & $\begin{array}{l}\text { Not } \\
\text { excellent }\end{array}$ & Excellent & & \\
\hline Final mean 24-h SBP (mmHg): (range), median & $\begin{array}{l}(109.5,173.7) \\
134.4\end{array}$ & $\begin{array}{l}(102.4,161.7) \\
128.8\end{array}$ & $132.9(2.4)$ & $131.6(2.5)$ & $-1.3(-8.1,5.6)$ & 0.71 \\
\hline Mean \pm standard deviation & $135.2 \pm 13.5$ & $129.5 \pm 14.8$ & & & & \\
\hline Change in mean 24-h SBP (mmHg): (range), median & $(-23.9,29.4) 1.2$ & $\begin{array}{l}(-26.6,18.0) \\
-0.4\end{array}$ & & & & \\
\hline Mean \pm standard deviation & $-1.1 \pm 13.1$ & $-1.1 \pm 11.2$ & & & & \\
\hline $\begin{array}{l}\text { Final DDD: (range), median } \\
\quad \text { Mean } \pm \text { standard deviation }\end{array}$ & $\begin{array}{l}(0.2,10.1) 3.0 \\
3.4 \pm 2.5\end{array}$ & $\begin{array}{l}(0.0,9.3) 2.5 \\
2.5 \pm 2.2\end{array}$ & $3.1(0.2)$ & $2.9(0.3)$ & $-0.3(-0.9,0.4)$ & 0.41 \\
\hline $\begin{array}{l}\text { Change in DDD: (range), median } \\
\text { Mean } \pm \text { standard deviation }\end{array}$ & $\begin{array}{l}(-3.0,3.1) 0.0 \\
0.0 \pm 1.3\end{array}$ & $\begin{array}{l}(-3.0,2.0) 0.0 \\
-0.3 \pm 1.1\end{array}$ & & & & \\
\hline $\begin{array}{l}\text { Final medication-adjusted SBP (mmHg): (range), } \\
\text { median } \\
\text { Mean } \pm \text { standard deviation }\end{array}$ & $\begin{array}{l}(120.0,240.1) \\
164.0 \\
166.9 \pm 28.4\end{array}$ & $\begin{array}{l}(112.8,236.1) \\
146.6 \\
149.4 \pm 25.6\end{array}$ & $161.3(3.5)$ & $156.9(3.7)$ & $-4.4(-14.7 .6 .0)$ & 0.40 \\
\hline $\begin{array}{l}\text { Change in medication-adjusted SBP ( } \mathrm{mmHg}) \text { : (range), } \\
\text { median } \\
\text { Mean } \pm \text { standard deviation }\end{array}$ & $\begin{array}{l}(-37.4,39.8) 2.1 \\
0.6 \pm 16.9\end{array}$ & $\begin{array}{l}(-50.6,20.5) \\
\quad-3.2 \\
-3.3 \pm 15.5\end{array}$ & & & & \\
\hline & & & & & Odds ratio $(95 \% \mathrm{CI})$ & \\
\hline Proportion with final nocturnal decline $>10 \%: N(\%)$ & $3(8.6 \%)$ & $5(22.7 \%)$ & & & $1.4(0.6,3.0)$ & 0.44 \\
\hline
\end{tabular}


end of the range. A sample size of 167 patients with sleep apnea in each group would have been required to demonstrate a 5-mmHg difference in mean 24-h systolic blood pressure among excellent versus not excellent CPAP users. A much larger sample size would have been required to identify a statistically significant relationship between intervention versus control group patients with a systolic blood pressure change in the $1.5-$ to $2.0-\mathrm{mmHg}$ range [35-38]. Second, this population of veterans with hypertension was treated in the VHA primary care setting, and the overwhelming majority was taking antihypertensive medications and their blood pressure was generally very well controlled. The VHA system has placed an emphasis on hypertension care quality, and blood pressure management is an important performance measure within the VHA primary care system nationwide. A recent study of the effect of CPAP on blood pressure among patients with resistant hypertension demonstrated a $3.1-\mathrm{mmHg}$ difference in 24-h systolic blood pressure, but in that study, baseline blood pressures were approximately $10 \mathrm{mmHg}$ higher than in our population (24-h systolic blood pressure of $144.2 \mathrm{mmHg}$ ) [39]. Third, we appreciate that hypertension may be attributed to many causes. Because we did not seek to identify etiologies of hypertension, we were not able to identify specific patients in whom sleep apnea may have been the primary etiology of the hypertension.

The primary limitation of the GoToSleep trial is its focus on the veteran population, which may limit generalizability to women as there were relatively few female patients in this study. The patients in this trial all had a history of cerebrovascular disease and hypertension, so these results should not be generalized to the acute cerebrovascular event setting - where sleep apnea may be more prevalent and where hemodynamic fluctuations may be more prominent [1-9, 13, 40, 41]. Another potential limitation is that although the NIHSS in this population ranged from 0 to 19 , the mean values of approximately 2 suggest that the population had relatively mild stroke severity. Therefore, these results may not be generalizable to a population of chronic cerebrovascular disease patients with more prominent neurological impairments.

Several randomized clinical trials and observational cohort studies have examined the use of CPAP in the cerebrovascular disease population for the purpose of improving post-stroke or post-TIA outcomes; in general, these studies have focused on patients in the acute or subacute event setting. The randomized controlled trials have all been relatively small, with sample sizes insufficient to identify changes in outcomes associated with treatment $[40,42,43]$. The largest of the randomized trials was conducted by Parra et al. [44] and followed $(N=126)$ acute stroke patients with sleep apnea over a 2-year period. The stroke rate was similar in both groups: $3 / 57(5.3 \%)$ fixed pressure CPAP and 3/69 (4.3\%) control $(p=1.0)$; however, the mean time from stroke onset to the first cardiovascular event was longer in the CPAP group: 15 months in the CPAP patients versus 8 months in the control patients $(p=0.044)$. Two randomized controlled trials evaluated the use of CPAP in subacute stroke patients and reported mixed results, finding improvements in several outcome domains for the CPAP group (e.g., depression) versus usual care, and also no statistically significant differences in several outcomes [45, 46].

In conclusion, this study identified both a high prevalence $(62 \%)$ of sleep apnea in a chronic post-stroke and post-TIA population with hypertension and a very low sleep apnea detection rate (9\%) for patients in the usual care group. This study further demonstrated that in-home diagnostic and treatment strategies can be effectively deployed to supplement sleep medicine services that are provided in a sleep laboratory. Although no published data support the use of CPAP among chronic (as opposed to acute) post-cerebrovascular event patients specifically for the reduction of vascular events, there is considerable evidence to support the treatment of sleep apnea in general to improve a variety of patient outcomes [35, 47]. Our findings add to the growing literature that suggests that the effect of CPAP on blood pressure is modest and likely only present in patients with uncontrolled hypertension. The study results provide a rationale for using polysomnography to identify sleep apnea among all patients post-stroke or post-TIA given its high prevalence, and suggest that support for CPAP adherence should persist over time, because many patients in the intervention group in this study continued to adapt to CPAP well beyond the first month of receiving a CPAP machine.

Acknowledgements This project was supported by the Department of Veterans Affairs Health Services Research and Development Service (VA HSR\&D; IIR-06-233-2); Dr. Mathias is supported by VA HSRD CDA $10-034$.

Compliance with ethical standards This study (NCT00984308) received institutional review board approval; patients provided written informed consent.

Open Access This article is distributed under the terms of the Creative Commons Attribution 4.0 International License (http:// creativecommons.org/licenses/by/4.0/), which permits unrestricted use, distribution, and reproduction in any medium, provided you give appropriate credit to the original author(s) and the source, provide a link to the Creative Commons license, and indicate if changes were made.

\section{References}

1. Wessendorf T, Teschler H, Wang Y-M, Konietzko N, Thilmann A (2000) Sleep-disordered breathing among patients with first-ever stroke. J Neurol 247:41-47

2. Turkington P, Bamford J, Wanklyn P, Elliott M (2002) Prevalence and predictors of upper airway obstruction in the first 24 hours after acute stroke. Stroke 33:2037-2042

3. Harbison J, Ford G, James O, Gibson G (2002) Sleep-disordered breathing following acute stroke. Q J Med 95:741-747 
4. Iranzo A, Santamaria J, Berenguer J, Sanchez M, Chamorro A (2002) Prevalence and clinical importance of sleep apnea in the first night after cerebral infarction. Neurology 58:911-916

5. Dyken M, Somers V, Yamada T, Ren Z, Zimmerman M (1996) Investigating the relationship between stroke and obstructive sleep apnea. Stroke 27:401-407

6. Bassetti C, Aldrich M (1999) Sleep apnea in acute cerebrovascular diseases: final report on 128 patients. Sleep 22:217-223

7. Parra O, Arboix A, Bechich S, García-Eroles L, Montserrat J, López J, Ballester E, Guerra J, Sopeña J (2000) Time course of sleep-related breathing disorders in first-ever stroke or transient ischemic attack. Am J Respir Crit Care Med 161:375-380

8. Sandberg O, Franklin K, Bucht G, Gustafson Y (2001) Sleep apnea, delirium, depressed mood, cognition, and ADL ability after stroke. J Am Geriatr Soc 49:391-397

9. Kapen S, Goldberg J, Wynter J (1991) The incidence and severity of obstructive sleep apnea in ischemic cerebrovascular disease. Neurology 41:125

10. Young T, Peppard P (2002) D G. Epidemiology of obstructive sleep apnea: a population health perspective. Am J Respir Crit Care Med 165:1217-1239

11. Botros N, Concato J, Mohsenin V, Selim B, Doctor K, Yaggi H (2009) Obstructive sleep apnea as a risk factor for type 2 diabetes. Am J Med 122:1122-1127

12. Yaggi HK, Concato J, Kernan WN, Lichtman JH, Brass LM, Mohsenin V (2005) Obstructive sleep apnea as a risk factor for stroke and death. NEJM 353:2034-2041

13. Mohsenin VVR (1995) Sleep apnea in patients with hemispheric stroke. Arch Phys Med Rehabil 76:71-76

14. Shah N, Yaggi H, Concato J, Mohsenin V (2010) Obstructive sleep apnea as a risk factor for coronary events or cardiovascular death. Sleep Breath $=$ Schlaf \& Atmung 14:131-136

15. Colten H, Abboud F, Block G, Boat T, Litt I, Mignot E, Miller R, Nieto J, Pack A, Parker K, Potolicchio S, Redline S, Reynolds C, Saper C (2006) Sleep disorders and sleep deprivation: an unmet public health problem

16. Kernan WN, Ovbiagele B, Black HR, Bravata DM, Chimowitz MI, Ezekowitz MD, Fang MC, Fisher M, Furie KL, Heck DV, Johnston SC, Kasner SE, Kittner SJ, Mitchell PH, Rich MW, Richardson D, Schwamm LH, Wilson JA (2014) Guidelines for the prevention of stroke in patients with stroke and transient ischemic attack: a guideline for healthcare professionals from the American Heart Association/American Stroke Association. Stroke 45:2160-2236

17. Bravata DMML, Cheng E, Arling G, Miech EJ, Damush T, Sico J, Phipps M, Yu Z, Zillich A, Reeves M, Johanning J, Chatuvedi S, Baye F, Snow K, Barnd J, Slaven J, Austin C, Ferguson J, Livingston D, Maryfield B, Graham G, Rhude R, Williams LS (2015) Quality of care for veterans with TIA and minor stroke. Stroke 46:ATMP73

18. Bravata D, Ferguson J, Miech E, Agarwal R, McClain V, Austin C, Struve F, Foresman B, Li X, Wang Z, Williams L, Dallas M, Couch C, Sico J, Fragoso C, Matthias M, Chumbler N, Myers J, Burrus N, Dube A, French D, Schmid A, Concato J, Yaggi H (2012) Diagnosis and treatment of sleep apnea in patients' homes: the rationale and methods of the "GoToSleep" randomized-controlled trial. J Clin Sleep Med 8:27-35

19. Netzer N, Stoohs R, Netzer C, Clark K, Strohl K (1999) Using the Berlin Questionnaire to identify patients at risk for the sleep apnea syndrome. Ann Intern Med 131:485-491

20. Chobanian A, Bakris G, Black H, Cushman W, Green L, Izzo JJ, Jones D, Materson B, Oparil S, Wright JJ, Roccella E (2003) Joint National Committee on prevention detection, evaluation, and treatment of high blood pressure. National Heart, Lung, and Blood Institute; National High Blood Pressure Education Program Coordinating Committee. Seventh report of the joint national committee on prevention, detection, evaluation, and treatment of high blood pressure. Hypertension (Dallas, Tex : 1979) 42:12061252

21. Goldstein LBMD (1994) Clinical assessment of stroke. JAMA 271: $1114-1120$

22. Johnston S (2002) Transient ischemic attack. NEJM 347:16871692

23. Johns M (1991) A new method for measuring daytime sleepiness: the Epworth sleepiness scale. Sleep 14:540-545

24. Johns M (1992) Reliability and factor analysis of the Epworth Sleepiness Scale. Sleep 15:376-381

25. Adams H, Davis P, Leira E, Chang K, Bendixen B, Clarke W, Woolson R, Hansen M (1999) Baseline NIH Stroke Scale score strongly predicts outcome after stroke: a report of the trial of org 10172 in acute stroke treatment (TOAST). Neurology 53:126-131

26. Goldstein L, Bertels C, Davis J (1989) Interrater reliability of the NIH stroke scale. Arch Neurol 46:660-662

27. Ohkubo T, Hozawa A, Yamaguchi J, Kikuya M, Ohmori K, Michimata M, Matsubara M, Hashimoto J, Hoshi H, Araki T, Tsuji I, Satoh H, Hisamichi S, Imai Y (2002) Prognostic significance of the nocturnal decline in blood pressure in individuals with and without high 24-h blood pressure: the Ohasama study. J Hypertens 20:2183-2189

28. Norwegian Institute of Public Health. 2013 Atc/ddd index 2013

29. Sleep Disorders Atlas Task Force (1992) EEG arousals: scoring rules and examples: a preliminary report from the sleep disorders atlas task force of the American Sleep Disorders Association. Sleep Med 15:173-184

30. Loube D, Gay P, Strohl K, Pack A, White D, Collop N (1999) Indications for positive airway pressure treatment of adult obstructive sleep apnea patients: a consensus statement. Chest 115:863866

31. Meoli A, Casey K, Clark R, Coleman J, Fayle R, Troell R, Iber C (2001) Hypopnea in sleep-disordered breathing in adults. Sleep Med 24:469-470

32. Hirshkowitz M, Littner M, Kuna S, Berry R, Norris M, Almenoff P (2003) Sleep-related breathing disorders: sourcebook. VHA, Milwaukee

33. Kotzian S, Stanek J, Pinter M, Grossmann W, Saletu M (2012) Subjective evaluation of sleep apnea is not sufficient in stroke rehabilitation. Top Stroke Rehabil 19:45-53

34. Srijithesh P, Shukla G, Srivastav A, Goyal V, Singh S, Behari M (2011) Validity of the Berlin Questionnaire in identifying obstructive sleep apnea syndrome when administered to the informants of stroke patients. J Clin Neurosci 18:340-343

35. Giles T, Lasserson T, Smith B, White J, Wright J, Cates C (2006) Continuous positive airways pressure for obstructive sleep apnoea in adults. Cochrane Database Syst Rev 3:CD001106

36. Bazzano L, Khan Z, Reynolds K, He J (2007) Effect of nocturnal nasal continuous positive airway pressure on blood pressure in obstructive sleep apnea. Hypertension (Dallas, Tex. : 1979) 50:417423

37. Haentjens P, Van Meerhaeghe A, Moscariello A, De Weerdt S, Poppe K, Dupont A, Velkeniers B (2007) The impact of continuous positive airway pressure on blood pressure in patients with obstructive sleep apnea syndrome: evidence from a meta-analysis of placebo-controlled randomized trials. Arch Intern Med 167:757764

38. Alajmi M, Mulgrew A, Fox J, Davidson W, Schulzer M, Mak E, Ryan C, Fleetham J, Choi P, Ayas N (2007) Impact of continuous positive airway pressure therapy on blood pressure in patients with obstructive sleep apnea hypopnea: a meta-analysis of randomized controlled trials. Lung 185:67-72

39. Martínez-García M, Capote F, Campos-Rodríguez F, Lloberes P, Diaz de Atauri M, Somoza M, Masa J, González M, Sacristán L, Barbé F, Durán-Cantolla J, Aizpuru F, Mañas E, Barreiro B, 
Mosteiro M, Cebrián J, de la Peña M, García-Río F, Maimó A, Zapater J, Hernández C, Grau SanMarti N, Montserrat J (2013) Spanish sleep network. Effect of CPAP on blood pressure in patients with obstructive sleep apnea and resistant hypertension: the HIPARCO randomized clinical trial. JAMA 310:2407-2415

40. Bravata D, Concato J, Fried T, Ranjbar N, Sadarangani T, McClain V, Struve F, Zygmunt L, Knight H, Lo A, Richerson G, Gorman M, Williams L, Brass L, Agostini J, Mohsenin V, Roux F, Yaggi H (2010) Auto-titrating continuous positive airway pressure for patients with acute transient ischemic attack: a randomized feasibility trial. Stroke 41:1464-1470

41. Bravata D, Concato J, Fried T, Ranjbar N, Sadarangani T, McClain V, Struve F, Zygmunt L, Knight H, Lo A, Richerson G, Gorman M, Williams L, Brass L, Agostini J, Mohsenin V, Roux F, Yaggi H (2011) Continuous positive airway pressure: evaluation of a novel therapy for patients with acute ischemic stroke. Sleep 34:1271-1277

42. Brown D, Chervin R, Kalbfleisch J, Zupancic M, Migda E, Svatikova A, Concannon M, Martin C, Weatherwax K, Morgenstern L (2011) Sleep apnea treatment after stroke (sats) trial: is it feasible? J Stroke Cerebrovasc Dis 2011:1-9

43. Hsu C, Vennelle M, Li H, Engleman H, Dennis M, Douglas N (2006) Sleep-disordered breathing after stroke: a randomised controlled trial of continuous positive airway pressure. J Neurol Neurosurg Psychiatry 77:1143-1149

44. Parra O, Sánchez-Armengol A, Bonnin M, Arboix A, CamposRodríguez F, Pérez-Ronchel J, Durán-Cantolla J, de la Torre G, González Marcos J, de la Peña M, Carmen Jiménez M, Masa F, Casado I, Luz Alonso M, Macarrón J (2011) Early treatment of obstructive apnoea and stroke outcome: a randomised controlled trial. Eur Respir J 37:1128-1136

45. Ryan C, Bayley M, Green R, Murray B, Bradley T (2011) Influence of continuous positive airway pressure on outcomes of rehabilitation in stroke patients with obstructive sleep apnea. Stroke 42: 1062-1067

46. Sandberg O, Franklin K, Bucht G, Eriksson S, Gustafson Y (2001) Nasal continuous positive airway pressure in stroke patients with sleep apnoea: a randomized treatment study. Eur Respir J 18:630 634

47. Epstein L, Kristo D, PJ Strollo, Friedman N, Malhotra A, Patil S, Ramar K, Rogers R, Schwab R, Weaver E, Weinstein M (2009) Adult obstructive sleep apnea task force of the American Academy of Sleep Medicine. Clinical guideline for the evaluation, management and long-term care of obstructive sleep apnea in adults. J Clin Sleep Med 5:263-276 